\title{
Exendin-4, but not glucagon-like peptide-1, is cleared exclusively by glomerular filtration in anaesthetised pigs
}

Received: 6 September 2005 / Accepted: 4 November 2005 / Published online: 31 January 2006

(C) Springer-Verlag 2006

\begin{abstract}
Aims/hypothesis: The insulinotropic hormone, glucagon-like peptide-1 (GLP-1), is rapidly degraded in vivo as a result of the combination of extensive enzymatic degradation and renal extraction. The GLP-1 receptor agonist, exendin-4, has a longer duration of action, and has recently been approved as a new agent for the treatment of type 2 diabetes mellitus. Exendin- 4 is less prone to enzymatic degradation, but it is still unclear what other factors contribute to the increased metabolic stability. Materials and methods: The overall metabolism of GLP1 and exendin- 4 was directly compared in anaesthetised pigs $(n=9)$. Results: Metabolism of GLP-1 (C-terminal RIA; $t_{1 / 2} 2.0 \pm 0.2 \mathrm{~min}$, metabolic clearance rate [MCR] $23.2 \pm 2.8 \mathrm{ml} \mathrm{min}^{-1} \mathrm{~kg}^{-1}$; N-terminal RIA; $t_{1 / 2} 1.5 \pm 0.2 \mathrm{~min}$, MCR $88.1 \pm 10.6 \mathrm{ml} \mathrm{min}{ }^{-1} \mathrm{~kg}^{-1}$ ) was significantly faster than the metabolism of exendin- $4\left(t_{1 / 2} 22.0 \pm 2.1 \mathrm{~min}\right.$, $p<0.0001$; MCR $\left.1.7 \pm 0.3 \mathrm{ml} \mathrm{min}^{-1} \mathrm{~kg}^{-1}, p<0.01\right)$. Differences in arteriovenous concentrations revealed organ extraction of GLP-1 by the kidneys (C-terminal $56.6 \pm$ 2.6\%; N-terminal $48.3 \pm 5.9 \%$ ), liver (N-terminal $41.4 \pm$ $3.8 \%$ ), and peripheral tissues (C-terminal $42.3 \pm 6.0 \%$; Nterminal $33.0 \pm 7.8 \%$ ), whereas organ extraction of exendin- 4 was limited to the kidneys $(21.3 \pm 4.9 \%)$. While the renal extraction of exendin- $4(6.9 \pm 2.5 \mathrm{pmol} / \mathrm{min}) \mathrm{did}$ not differ significantly from the amount undergoing glomerular filtration $(8.4 \pm 2.0 \mathrm{pmol} / \mathrm{min})$, the renal extraction of C-terminal GLP-1 $(9.0 \pm 1.1 \mathrm{pmol} / \mathrm{min})$, exceeded the amount which could be accounted for by glomerular filtration $(4.2 \pm 0.5 \mathrm{pmol} / \mathrm{min}, p<0.0005)$. Conclusions/ interpretation: In addition to an increased resistance to enzymatic degradation, the increased stability of exendin-4 is the result of reduced differential organ extraction com-
\end{abstract}

\footnotetext{
L. Simonsen · J. J. Holst · C. F. Deacon $(\bowtie)$ Department of Medical Physiology, Panum Institute, University of Copenhagen, DK-2200 Copenhagen, Denmark e-mail: Deacon@mfi.ku.dk Tel.: +45-3532-7523

Fax: $+45-3532-7537$
}

pared to GLP-1. The data suggest that in the anaesthetised pig, extraction occurs only in the kidney and can be fully accounted for by glomerular filtration.

Keywords Dipeptidyl peptidase IV · Exendin-4 · Glomerular filtration rate · Glucagon-like peptide-1 · Incretin · Kidney - Metabolism ·

Neutral endopeptidase 24.11

Abbreviations DPPIV: dipeptidyl peptidase IV . GIP: glucose-dependent insulinotropic polypeptide . GLP-1: glucagon-like peptide-1 - MCR: metabolic clearance rate - NEP: neutral endopeptidase 24.11 . PAH: para-aminohippuric acid - RPF: renal plasma flow

\section{Introduction}

Glucagon-like peptide 1 (GLP-1) is an incretin hormone, which is released from the $\mathrm{L}$ cells of the distal intestine in response to nutrients. It possesses a number of beneficial antidiabetic properties, (reviewed in [1]), which has raised interest in using GLP-1 therapeutically to treat type 2 diabetes mellitus. However, the usefulness of the native peptide is limited by its metabolic instability. Biologically active GLP-1 has an apparent plasma half-life of only 12 min in humans [2], which means that continuous infusion is required to maintain efficacy [3, 4]. Enzymatic degradation has been identified as a major contributor to the metabolic instability of GLP-1. The ubiquitous enzyme, dipeptidyl peptidase IV (DPPIV), rapidly cleaves a dipeptide from the $\mathrm{N}$-terminus $[5,6]$, rendering the peptide inactive, because an intact $\mathrm{N}$-terminus is required for receptor activation [7]. However, DPPIV may not be the only enzyme involved in the degradation of GLP-1. In vitro studies have demonstrated that neutral endopeptidase 24.11 (NEP) can cleave GLP-1 at multiple sites in both the central and more C-terminal parts of the peptide [8], suggesting a potential role for NEP in the in vivo metabolism of GLP-1. In support of this, a study from this laboratory recently found that NEP inhibition increases the metabolic stability 
of exogenously administered GLP-1 in anaesthetised pigs [9]. In addition to the substantial enzymatic degradation, several studies have pointed to the kidney as an important mediator in the final elimination of GLP-1 and its metabolites. Autoradiographic studies demonstrated a tendency for GLP-1 to accumulate in the kidneys shortly after intravenous administration [10], while studies in nephrectomised rats and in patients with renal failure revealed reduced clearance of GLP-1 [11, 12]. These findings have prompted much research into identifying metabolically stable analogues/derivatives of GLP-1 suitable for therapeutic use. One such compound is exenatide, a synthetic peptide identical to the naturally occurring peptide exendin-4, which has recently been approved by the FDA for the treatment of type 2 diabetes mellitus. Exendin- 4 is a 39amino-acid GLP-1 receptor agonist that shares $53 \%$ sequence homology with GLP-1; the resemblance being most pronounced in the N-terminal [13]. The sequence homology is less pronounced in the C-terminal region, and exendin- 4 also has a nine-amino-acid extension. Exendin-4 has a half-life of $26 \mathrm{~min}$ in humans after intravenous infusion [14], but the precise factors that contribute to the slower metabolic clearance of exendin-4 relative to GLP-1 have not been examined in detail. In vitro studies have shown that exendin-4 is apparently more resistant to enzymatic degradation than GLP-1 [15]. It is hardly degraded by DPPIV and is a poor substrate for other enzymes, including NEP [8]. Although the in vivo metabolism of exendin-4 has not been studied in detail, it appears that the kidneys may play an important role in its elimination [14].

The aim of the present study was to compare directly the overall metabolism of GLP-1 and that of exendin-4, in vivo, with specific emphasis on the renal metabolism. Studies were carried out in anaesthetised pigs using a protocol which has previously been used to reveal metabolic degradation of GLP-1 [6], glucose-dependent insulinotropic polypeptide (GIP) [16] and glucagon [17].

\section{Materials and methods}

Animals and surgical procedure

The animal studies were in accordance with international guidelines (National Institutes of Health publication no. 85-23, revised 1985, and Danish legislation governing animal experimentation, 1987), and were carried out after permission had been granted by the National Superintendent for Experimental Animals. Female pigs $(n=9)$ of the LYD strain (Lars Jonssen, Lynge, Denmark), weighing approximately $30 \mathrm{~kg}$ and fasted overnight were used in this study. After premedication with Ketalar $(10 \mathrm{mg} / \mathrm{kg}$ ketamine hydrochloride; Pfizer, Ballerup, Denmark), the animals were anaesthetised with intravenous $\alpha$-chloralose (66 mg/kg; Sigma, Brøndby, Denmark), and ventilated with intermittent positive pressure with $\mathrm{N}_{2} \mathrm{O} / \mathrm{O}_{2}$. After midline laparotomy, catheters were placed in both ureters, and subsequently, vascular catheters were placed in the right carotid artery, the left renal vein, the right hepatic vein, the left femoral vein, the portal vein, and the pulmonary artery as previously described [6]. Cannulas were inserted into the veins of both ears, one was used for infusion of saline at a rate of $5 \mathrm{ml} / \mathrm{min}$, and additional chloralose as necessary, and the other was used for peptide infusions. Following the surgical procedure, the animals were heparinised and left undisturbed for $30 \mathrm{~min}$.

\section{Experimental procedure}

\section{Peptide metabolism}

All animals received two peptide infusions; one of GLP1(7-36)amide (Bachem, Weil am Rhein, Germany) and one of exendin-4 (Bachem). Because of the anticipated long half-life of exendin-4, these studies were not carried out as cross-over studies. Two basal blood samples were taken from the carotid artery, at -10 and $0 \mathrm{~min}$, after which, an intravenous infusion of GLP-1(7-36)amide was initiated. The peptide (dissolved in $0.04 \mathrm{~mol} / 1$ phosphate buffer $\mathrm{pH} 7.5$ containing 1\% human serum albumin [Merck, Darmstadt, Germany]), was administered using an automatic syringe pump for $30 \mathrm{~min}$ at a rate of 2 pmol min ${ }^{-1} \mathrm{~kg}^{-1}$. During the infusion, carotid arterial blood samples $(3 \mathrm{ml})$ were taken every $5 \mathrm{~min}$. After $20 \mathrm{~min}$, when steady-state arterial peptide concentrations had been attained, simultaneous blood samples $(3 \mathrm{ml})$ were taken from the carotid artery and all the veins, followed by a duplicate set of samples 5 min later. After $30 \mathrm{~min}$, the GLP-1 infusion was stopped and further arterial blood samples were taken at 1, 2, 4, 6, 10, 15 and 20 min. Thirty minutes after the end of the GLP-1 infusion, an intravenous infusion of exendin- 4 was started. The peptide (dissolved in $0.04 \mathrm{~mol} / 1$ phosphate buffer $\mathrm{pH}$ 7.5 containing $1 \%$ human serum albumin) was infused for $40 \mathrm{~min}$ at a dose of $0.2 \mathrm{pmol} \mathrm{min}{ }^{-1} \mathrm{~kg}^{-1}$, preceded by a bolus intravenous injection of $6 \mathrm{pmol} / \mathrm{kg}$. During the exendin-4 infusion, carotid arterial blood samples $(3 \mathrm{ml})$ were taken every $10 \mathrm{~min}$ and a duplicate set of venous blood samples $(3 \mathrm{ml})$ and carotid arterial blood samples were taken at 30 and $35 \mathrm{~min}$. Following termination of the infusion, arterial blood samples were taken at 10, 20, $30,45,60,90,120$ and $150 \mathrm{~min}$.

Blood samples were collected into chilled tubes containing EDTA (Merck) $(7.4 \mathrm{mmol} / \mathrm{l}$ final concentration), and valine pyrrolidide $(0.01 \mathrm{mmol} / \mathrm{l}$ final concentration, a gift from Richard D. Carr, Novo Nordisk A/S, Bagsværd, Denmark). The tubes were stored on ice during the experiment until centrifugation at $4^{\circ} \mathrm{C}$, after which plasma was separated and kept at $-20^{\circ} \mathrm{C}$ until analysis.

A separate group of control animals $(n=3)$ underwent the same procedure, except for receiving vehicle in place of the peptide infusions. 


\section{Renal haemodynamics}

Animals received ${ }^{14} \mathrm{C}$-labelled inulin and ${ }^{3} \mathrm{H}$-labelled paraaminohippuric acid (PAH) infusions throughout the experiments. Infusions were started immediately after insertion of the catheters into the ureters with a bolus injection of $\left[{ }^{3} \mathrm{H}\right] \mathrm{PAH}$ and $\left[{ }^{14} \mathrm{C}\right]$ inulin (Perkin Elmer, Wellesley, USA; $740 \mathrm{kBq}$ and $110 \mathrm{kBq}$, respectively, dissolved in $0.04 \mathrm{~mol} / \mathrm{l}$ phosphate buffer $\mathrm{pH} 7.5$ ), followed by continuous intravenous infusions, $\left(\left[{ }^{3} \mathrm{H}\right] \mathrm{PAH} \quad 720 \mathrm{kBq} / \mathrm{h} ; \quad\left[{ }^{14} \mathrm{C}\right]\right.$ inulin $85 \mathrm{kBq} / \mathrm{h}$ ), allowing steady-state levels to be reached while the other catheters were being placed. Urine samples from each kidney were collected for 20-min periods: (1) during the GLP-1 infusion ( $t=5-25 \mathrm{~min}$ ); (2) between the peptide infusions ( $t=40-60 \mathrm{~min})$; (3) during the exendin-4 infusion ( $t=75-95 \mathrm{~min})$; (4) and following the exendin-4 infusion $(t=125-145 \mathrm{~min}$ and $t=230-250 \mathrm{~min})$. At the end of each urine collection period, an extra $0.5 \mathrm{ml}$ of blood was taken from the renal vein and the carotid artery. Urine volumes were recorded, and both urine and plasma samples were measured for $\beta$-radioactivity $\left(\left[{ }^{3} \mathrm{H}\right] \mathrm{PAH}, 0-12 \mathrm{keV}\right.$ and $\left[{ }^{14} \mathrm{C}\right]$ inulin, $\left.12-156 \mathrm{keV}\right)$ to allow the calculation of renal plasma flow (RPF) and glomerular filtration rate (GFR).

The total volume of blood taken $(150 \mathrm{ml})$ did not exceed $5 \%$ of the total blood volume for a $30-\mathrm{kg}$ animal and this fluid loss was replaced with saline following each blood sample. Blood pressure and heart rate were monitored throughout the experiments, and remained stable, as seen in previous experiments [6].

\section{Hormonal analysis}

Two different RIAs were used for the analysis of GLP-1 to detect terminus-specific degradation. Antiserum 89390 is highly specific for the intact amidated C-terminal of GLP-1 (7-36)amide. It shows full cross-reactivity with GLP-1 peptides truncated at the N-terminus, $<0.5 \%$ cross-reactivity with GLP-1 peptides truncated at the C-terminus (i.e. GLP-1(7-33), GLP-1(7-34) and GLP-1(7-35)) and no cross-reactivity with exendin-4. The detection limit was $<1 \mathrm{pmol} / 1$ [18, 19]. Antiserum Her4 (obtained from Dr Dominique Bataille, Inserm U 376, Montpellier, France) requires the intact $\mathrm{N}$-terminus of the GLP-1 molecule. It showed no measurable cross-reaction with peptides that were extended at the $\mathrm{N}$-terminus, $<1 \%$ cross-reaction with peptides truncated at the N-terminus, including GLP-1(936)amide, and no cross-reactivity with exendin-4. Crossreactivity with GLP-1 peptides truncated at the C-terminus was $100 \%$. The detection limit was below 2 pmol/l. For both GLP-1 assays, the intra- and inter-assay coefficients of variation for concentrations covering the working ranges of the assay were $<6$ and $10-15 \%$, respectively. Plasma samples analysed for GLP-1 immunoreactivity were extracted by ethanol precipitation $(70 \%, \mathrm{vol} / \mathrm{vol}$, final concentration for C-terminal GLP-1, and $80 \% \mathrm{vol} / \mathrm{vol}$, final concentration for N-terminal GLP-1) before analysis. The recovery of GLP-1, added to plasma before extraction (in concentrations covering the whole standard curve), was $75 \%$ for C-terminal GLP-1 [20], and $80 \%$ for N-terminal GLP-1.

Since, for exendin-4, little N-terminally directed degradation is expected [15], the immunoreactivity of exendin- 4 was determined with competitive RIA, using a single antibody, which is directed towards the central or Cterminal region of the peptide (a gift from M. Ghatei, Endocrine Unit, Hammersmith Hospital, London, UK), which was raised against exendin-4 conjugated to human serum albumin [14]. The tracer used was ${ }^{125}$ I-labelled exendin(9-39) (Perkin Elmer). No cross-reactivity was observed with either GLP-1, glucagon or GIP, whereas the antibody cross-reacted $100 \%$ with exendin(9-39). The intra- and inter-assay coefficients of variation at concentrations covering the working range of the assay were $<5$ and $10-15 \%$, respectively, and the detection limit was $<1 \mathrm{pmol} / 1$. Plasma samples were analysed directly in unextracted plasma diluted 10-fold with assay buffer.

\section{Calculations and statistical analysis}

The renal clearance of $\left[{ }^{14} \mathrm{C}\right]$ inulin was used to estimate the GFR for each kidney using the formula $C_{\text {in }}=\mathrm{GFR}=\left(U_{\text {in }} D\right) /$ $A_{\text {in }}$, where $U_{\text {in }}$ is $\left[{ }^{14} \mathrm{C}\right]$ inulin activity in the urine, $A_{\text {in }}$ is $\left[{ }^{14} \mathrm{C}\right]$ inulin activity in the arterial plasma and $D$ is the diuresis. The renal clearance of $\left[{ }^{3} \mathrm{H}\right] \mathrm{PAH}$ was used to estimate the effective RPF. For each kidney, the clearance of PAH was determined as $C_{\mathrm{PAH}}=\left(U_{\mathrm{PAH}} D\right) / A_{\mathrm{PAH}}$. The extraction fraction of $\left[{ }^{3} \mathrm{H}\right] \mathrm{PAH}$ was determined for the left kidney to estimate the efficiency of renal tubular secretion, using the formula $E_{\mathrm{PAH}}=\left(A_{\mathrm{PAH}}-V_{\mathrm{PAH}}\right) / A_{\mathrm{PAH}}$, where $V_{\mathrm{PAH}}$ is $\left[{ }^{3} \mathrm{H}\right] \mathrm{PAH}$ activity in the renal vein, which is used to calculate the 'true' $\mathrm{RPF}=C_{\mathrm{PAH}} / E_{\mathrm{PAH}}$.

For each animal, the organ extractions of exendin- 4 and GLP-1 were calculated from arteriovenous concentration differences, as described in detail previously [6]. The pulmonary extraction was calculated as the concentration difference between the pulmonary artery and the carotid artery, while for determination of the hepatic extraction, the hepatic blood flow was calculated on the assumption that $75 \%$ originates from the portal vein and $25 \%$ originates from the carotid artery.

The plasma half-life of GLP-1 and exendin-4 was determined from the elimination phase of the carotid artery plasma profile (after subtraction of basal concentrations in the arterial sample before the start of the peptide infusion, and conversion to natural logarithms followed by linear regression). The metabolic clearance rate (MCR) was determined from the actual infusion rates using the formula $\mathrm{MCR}=$ infusion rate $/ A_{\text {carotid }}$.

The renal extraction of each peptide was calculated as: renal extraction $=\mathrm{RPF} \times\left(A_{\text {carotid }}-V_{\text {renal }}\right)$ and the maximum amount filtered was calculated as: amount filtered= $\mathrm{GFR} \times A_{\text {carotid. }}$.

The renal clearance rate was calculated as: renal clearance rate $=\left(\left(A_{\text {carotid }}-V_{\text {renal }}\right) / A_{\text {carotid }}\right) \times \mathrm{RPF}$. 
Data are expressed as mean \pm SEM and analysed by analysis of variance (ANOVA) and $t$-test for paired and unpaired data as appropriate. Differences resulting in $p<0.05$ were considered significant. Statistics were performed using Stastistica 6.0 for Windows (Statsoft, Tulsa, OK, USA).

\section{Results}

In vivo half-life and metabolic clearance rate

The plasma profile of exogenous GLP-1 ( $n=9$, Fig. 1) revealed significantly higher C-terminal GLP-1 immunoreactivity levels than N-terminal GLP-1 immunoreactivity $(p<0.001$, paired $t$-test). The plasma half-life tended to be shorter when determined with the N-terminal $\left(t_{1 / 2} 1.5 \pm\right.$ $0.2 \mathrm{~min})$ as compared to the C-terminal GLP-1 RIA ( $t_{1 / 2}$ $2.0 \pm 0.2 \mathrm{~min}$ ), although this was not significant $(p=0.1)$, and N-terminal GLP-1 immunoreactivity was cleared significantly faster (MCR N-terminal $88.1 \pm 10.6 \mathrm{ml} \mathrm{min}^{-1} \mathrm{~kg}^{-1}$, MCR C-terminal $23.3 \pm 2.8 \mathrm{ml} \mathrm{min}^{-1} \mathrm{~kg}^{-1}, p<0.0001$, twoway ANOVA). Plasma concentrations of exendin-4 $(n=9)$ are shown in Fig. 2. Exendin-4 was significantly more stable than GLP-1 $(p<0.01$, one-way ANOVA followed by paired $t$-test; $t_{1 / 2} 22.0 \pm 2.1 \mathrm{~min}$; MCR $1.7 \pm 0.3 \mathrm{ml} \mathrm{min}^{-1} \mathrm{~kg}^{-1}$ ).

\section{Organ extraction}

The immunoreactivity of plasma GLP-1 and exendin-4 during the peptide infusions is given in Table 1, and the net balance, as percent extraction across the different organs, is illustrated in Fig. 3. There was no significant organ extraction of GLP-1 across the lungs or the intestine, whereas extraction across the kidneys and the hind leg (representing muscular, connective, and adipose tissues)

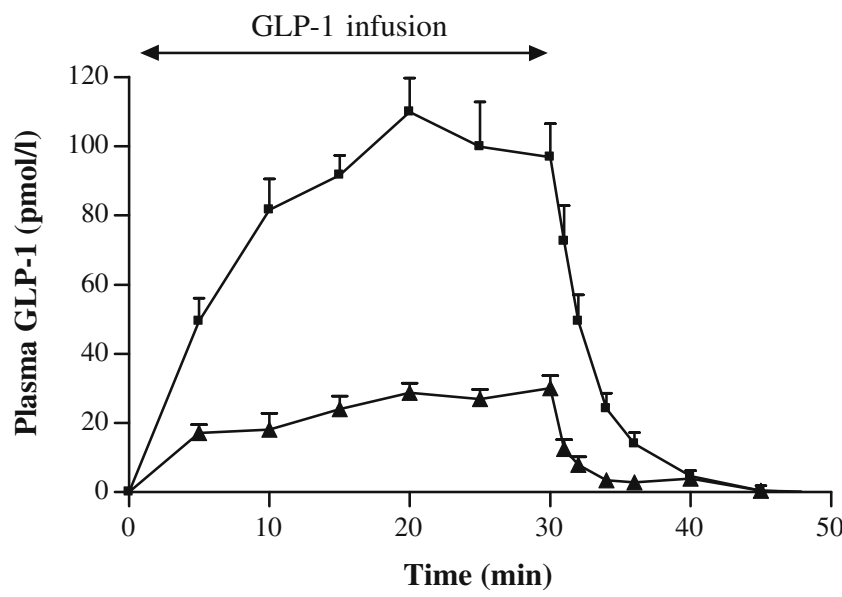

Fig. 1 The plasma concentration profile of GLP-1 in the carotid artery $(n=9)$, measured with a C-terminal RIA (89390) (squares) and an N-terminal RIA (Her4) (triangles), during and following the GLP-1 infusion. Data are means \pm SEM. During steady state, the Cterminal immunoreactivity of GLP-1 was markedly higher than the N-terminal immunoreactivity of GLP-1, $p<0.001$

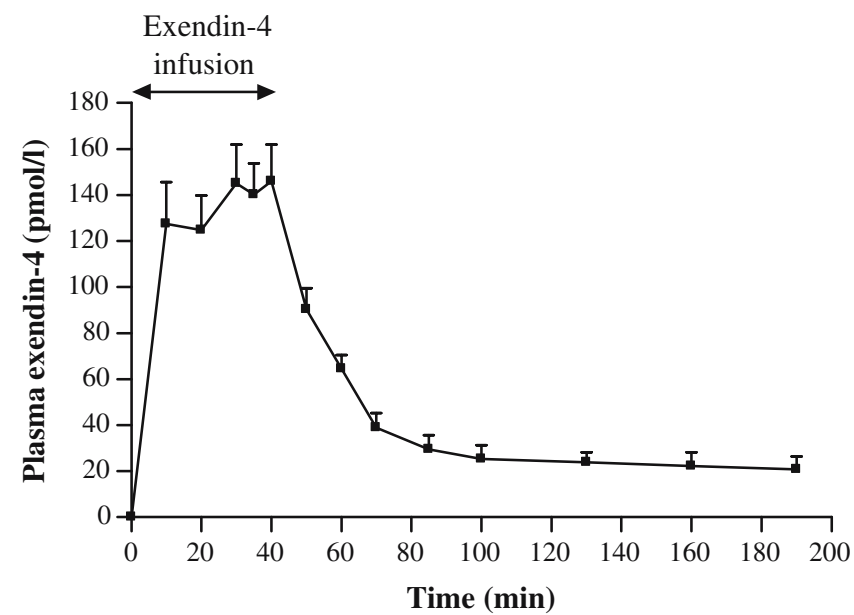

Fig. 2 The plasma profile of exendin- $4(n=9)$ in the carotid artery during and following the exendin- 4 infusion. Data are means \pm SEM

was observed with both assays. In addition, significant extraction of N-terminal GLP-1 immunoreactivity was detected in the liver. Extraction of exendin-4 was detected only in the kidney.

\section{Renal clearance}

In the control animals $(n=3), \mathrm{RPF}$ and GFR were stable and did not change significantly over the 250-min experimental period (two-way ANOVA, data not shown). Furthermore, there was no significant difference in renal function between the right (non-catheterised) and left (catheterised) kidney (GFR, $1.5 \pm 0.2 \mathrm{vs} 1.3 \pm 0.1 \mathrm{ml} \mathrm{min}^{-1} \mathrm{~kg}^{-1}$; effective $\mathrm{RPF}, 2.7 \pm 0.3$ vs $2.4 \pm 0.3 \mathrm{ml} \mathrm{min}^{-1} \mathrm{~kg}^{-1}$, right and left, respectively; $p=0.2$, paired $t$-test). For GLP-1, the renal clearance rate (C-terminal $5.2 \pm 0.9 \mathrm{ml} \mathrm{min}{ }^{-1} \mathrm{~kg}^{-1} ; \mathrm{N}$ terminal $4.2 \pm 0.9 \mathrm{ml} \mathrm{min}^{-1} \mathrm{~kg}^{-1}$ ) accounted for only a small

Table 1 Plasma immunoreactivity of GLP-1 and exendin-4 during peptide infusions

\begin{tabular}{lccl}
\hline & Exendin-4 & GLP-1 & GLP-1 \\
\cline { 3 - 3 } & & C-terminal & N-terminal \\
\hline Carotid artery & $143.7 \pm 15.2$ & $110.6 \pm 9.3$ & $34.7 \pm 3.2$ \\
Femoral vein & $143.6 \pm 14.2$ & $63.6 \pm 7.6^{*}$ & $22.1 \pm 3.1^{*}$ \\
Renal vein & $107.2 \pm 14.4^{*}$ & $48.1 \pm 4.2^{*}$ & $17.0 \pm 2.4^{*}$ \\
Pulmonary artery & $135.7 \pm 13.3$ & $112.2 \pm 10.9$ & $40.1 \pm 2.5$ \\
Portal vein & $137.4 \pm 15.5$ & $111.3 \pm 9.3$ & $33.4 \pm 5.9$ \\
Hepatic blood supply & $139.3 \pm 14.8$ & $112.0 \pm 8.9$ & $33.3 \pm 4.9$ \\
Hepatic vein & $142.7 \pm 16.1$ & $98.9 \pm 9.0$ & $20.8 \pm 3.5^{*}$ \\
\hline
\end{tabular}

The plasma concentrations (pmol/1) of GLP-1, measured with a Cterminal (89390) and an N-terminal (Her4) RIA, and of exendin-4. GLP-1 is given as the sum of the endogenous and the exogenous concentrations. The hepatic blood supply was calculated on the assumption that $75 \%$ originates from the portal vein and $25 \%$ is of arterial origin. Data are means $\pm \mathrm{SEM}$

${ }^{*} p<0.05$ indicates significant difference from the immunoreactivity in the carotid artery or the hepatic blood supply 


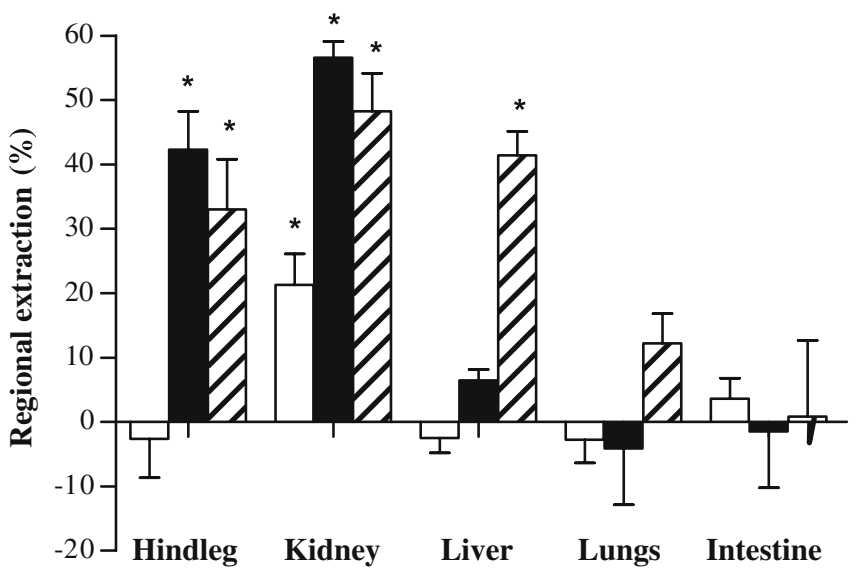

Fig. 3 Regional extraction of exendin-4 (white bars), GLP-1 measured with a C-terminal (89390) RIA (black bars) and GLP-1 measured with an N-terminal (Her4) RIA (hatched bars), during peptide infusions. The extraction is calculated as the difference in arteriovenous concentration divided by the arterial concentration. The hepatic blood supply was calculated on the assumption that $75 \%$ originates from the portal vein and $25 \%$ is of arterial origin. Data are means \pm SEM. ${ }^{*} p<0.05$ indicates net extraction of peptide

part of the overall metabolic clearance rate, amounting to $23.0 \pm 2.5 \%$ for C-terminal and $7.2 \pm 3.3 \%$ for $\mathrm{N}$-terminal immunoreactivity. In contrast, for exendin-4, the renal clearance rate $\left(3.0 \pm 1.0 \mathrm{ml} \mathrm{min}{ }^{-1} \mathrm{~kg}^{-1}\right)$ did not differ significantly from its metabolic clearance rate $(1.7 \pm 0.3 \mathrm{ml}$ $\left.\min ^{-1} \mathrm{~kg}^{-1}\right)$. Further analysis of the renal clearance showed that the renal extraction ( $\mathrm{pmol} / \mathrm{min}$ ) of C-terminal GLP-1, calculated using the simultaneously measured RPF, exceeded the maximal amount that could be explained by glomerular filtration by a factor of 2 (Fig. 4). In contrast, glomerular filtration of N-terminal GLP-1 could completely explain its renal clearance. Similarly, for exendin-4, the total renal extraction did not differ significantly from the amount which could be accounted for by glomerular filtration.

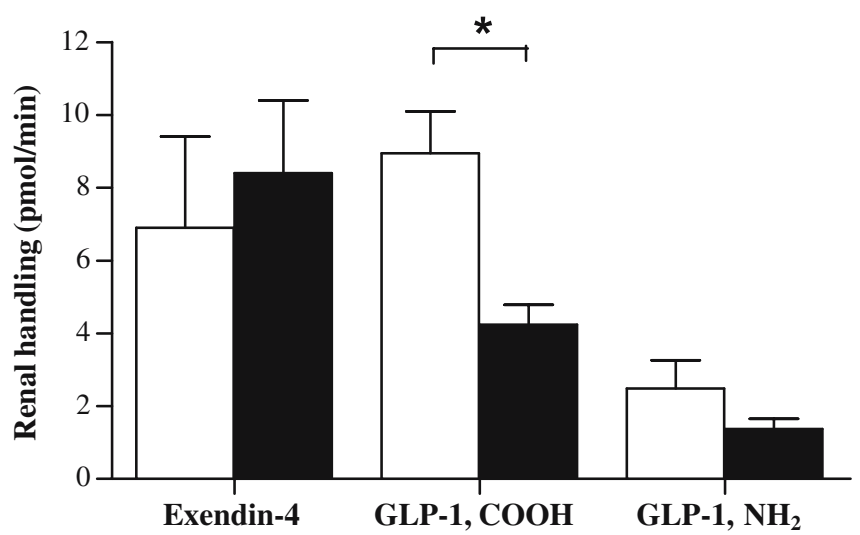

Fig. 4 The total renal clearance rate (white bars) of GLP-1, measured with a C-terminal (89390) RIA and an N-terminal (Her4) RIA, and of exendin-4, calculated from the simultaneously measured renal plasma flow, compared to the maximal amount filtered (black bars), calculated from the actual glomerular filtration rate. Data are means \pm SEM. $* p<0.05$ difference between clearance rate and filtration rate

\section{Discussion}

In the present study we directly compared the metabolism of GLP-1 and exendin-4 in vivo using anaesthetised pigs. Particular emphasis was placed on investigating the renal metabolism, because it has been suggested that the kidneys play an important role in the clearance of both peptides $[6,11,14]$.

The use of specific terminally directed assays for GLP-1 sheds light on the degradation taking place, as discussed previously [6], and explains why N-terminal immunoreactivity was lower than $\mathrm{C}$-terminal immunoreactivity during the infusion, because the product of DPPIV-mediated degradation, GLP-1(9-36)amide is not detected by the Nterminal assay. The overall metabolism of GLP-1 was significantly faster than that of exendin- 4 , giving rise to a 10 -fold longer plasma survival time for the latter $[2,6,14$, 21]. Part of the difference in metabolic stability between these two peptides, which share 53\% sequence homology, is the result of their different susceptibility to enzymatic degradation. Thus, GLP-1 is degraded initially by DPPIV and subsequently by other enzymes, including NEP $[8,15]$. Exendin-4, however, is reported to be more resistant to enzymatic degradation, and indeed, when incubated in the presence of kidney brush border membranes, which are especially rich in a variety of ectopeptidase activities [22], exendin-4 is remarkably stable, with a rate of proteolysis which is several orders of magnitude less than that of GLP1 [15]. As a result of the presence of a penultimate Nterminal glycine in exendin-4, compared with an alanine in GLP-1, exendin-4 is not degraded significantly by DPPIV [15]. Exendin-4 is also a poor substrate in vitro for NEP, whereas GLP-1 is rapidly degraded [8]. Furthermore, it is noteworthy that other peptides, which are structurally similar to GLP-1, show differential susceptibility to DPPIV in vitro $(\mathrm{GLP}-1 \approx \mathrm{GIP}>\mathrm{GLP}-2)[5,23]$, which does not correlate with their N-terminal half-lives in vivo (GLP$1<\mathrm{GIP} \approx \mathrm{GLP}-2)[2,24]$. Thus, GIP undergoes proteolysis in the presence of kidney brush border membranes at a rate resembling that of GLP-1 [15], even though the overall in vivo metabolism of GIP is much slower than that of GLP-1 $[6,16]$. This susceptibility of GLP-1 towards degradation in vivo, compared to peptides that, judged from their sequence and in vitro kinetic data, ought to be cleaved at a similar rate, indicates that, in addition to differences in primary structure, other features such as differences in secondary structure may render GLP-1 particularly prone to cleavage. With regard to exendin-4, it could be speculated that the tertiary structure, formed by the C-terminal extension [25], may help protect it from degradation not only because of the increased size of the peptide (i.e. NEP has a preference for smaller substrates [26]), but also by simply hindering the access of substrate to enzymes.

The variation in both the concentration and the particular type of enzymes located in the different tissues, combined with the high susceptibility of GLP-1 (in contrast to the general resistance of exendin-4) towards ectopeptidases may, therefore, partly explain the differential organ extraction of these two peptides observed in this study. As 
previously reported [6], the extraction pattern for GLP-1 is complex, involving hepatic, peripheral and renal extraction, whereas, earlier assumptions that the kidneys are the only clearance site for exendin-4 [14, 27] were confirmed. Thus, hepatic clearance of GLP-1 can be fully accounted for by DPPIV-mediated degradation because only Nterminal degradation is observed and DPPIV is abundant on hepatocytes [28], whereas the peripheral elimination of GLP-1 is a combination of C-terminal and N-terminal degradation, which may involve DPPIV in combination with other ectopeptidases, such as NEP, which are insufficient to affect the metabolism of exendin- 4 . In addition to this extracellular metabolism, mediated via enzymes found within the blood plasma, on the luminal side of the vascular endothelium and on extravascular sites within the tissues, peptide hormones may be degraded intracellularly following endocytosis, or subject to glomerular filtration and subsequent tubular degradation. The renal extraction fraction of GLP-1 (40-60\%) clearly exceeded that of exendin-4 $(\sim 20 \%)$, suggesting that a differential renal handling of the two peptides may also contribute to the greater metabolic stability of exendin- 4 . This appears to be the result of a genuine difference, and not secondary to changes in renal function over time, because GFR and RPF were monitored and found to be stable over the duration of the experiments. It was also verified that the presence of the non-obstructing vascular catheter in the renal vein did not affect GFR or RPF in the left kidney, because there was no difference between the two kidneys in these respects. Moreover, although there is evidence that GLP-1 may increase GFR [29], and raise blood pressure and heart rate in rats [30], when administered in very high concentrations that result in plasma concentrations clearly exceeding physiological levels as in the present study, these parameters (blood pressure, heart rate, GFR, and RPF) remained stable and were not altered by the peptide infusions. It is, therefore, reasonable to speculate that several mechanisms may be involved in the renal handling of peptide hormones, and this explains the differential degree of extraction that occurs for GLP-1 and exendin-4. These mechanisms may be similar to those previously described for the renal handling of the structurally related peptide, glucagon, which has been investigated in some detail and reported to consist of glomerular filtration followed by extensive catabolism, mediated by brush border peptidases and reabsorption of amino acids in the proximal tubules [31]. Small peptide fragments can also be reabsorbed in the proximal tubules and subsequently degraded intracellularly [32], while, in addition, it has also been indicated that peritubular uptake could be involved. The extent to which this occurs in the normally filtering kidney has not been assessed, but it seems to play a significant role in the non-filtering kidney [33].

In the present study, the finding that the renal clearance of C-terminal GLP-1 immunoreactivity exceeds the amount that can be explained by glomerular filtration is in contrast with the fact that renal clearance of $\mathrm{N}$-terminal
GLP-1 immunoreactivity is fully accounted for by glomerular filtration. These findings are, however, in good agreement with previously reported results [11]. In patients with renal insufficiency, the MCR of C-terminal GLP-1 was reduced, whereas the clearance of $\mathrm{N}$-terminal immunoreactivity was relatively unaffected. Thus, it was concluded that the kidneys are not the primary site of DPPIV-mediated metabolism of GLP-1, but are important in the final elimination of its metabolites [11]. Only one study has sought to investigate the mechanisms behind the renal metabolism of GLP-1 and suggested that both glomerular filtration and tubular metabolism take place [12]. In rats, the half-life of GLP-1 was increased following bilateral ureteral ligation or nephrectomy, indicating that renal extraction of GLP-1 is not always dependent on the occurrence of glomerular filtration. The same study also showed that renal clearance by the isolated kidney exceeded the simultaneously measured GFR, in agreement with the present study. Paradoxically however, renal clearance was almost eliminated in the non-filtering kidney [12], further underlining that additional studies are required to clarify precisely which mechanisms are involved.

In contrast to GLP-1, our data suggest that glomerular filtration may account for the entire renal metabolism of exendin- 4 , because the renal clearance rate of exendin- 4 was not significantly different from the GFR. Having identified the kidneys as the only clearance site of exendin4 , these observations suggest that exendin-4 is cleared solely by glomerular filtration. It has previously been speculated that this is the case $[14,27]$ but in those studies the actual GFR was not measured. However, it should also be borne in mind that the conclusion that glomerular filtration is the only extraction route of exendin- 4 is based on the assumption that exendin- 4 is filtered freely. Although the size of exendin-4 ought not to be a barrier, it cannot be excluded that other properties of the peptide, such as binding to plasma albumin, could affect its ability to pass the filtration barrier. Experiments from this laboratory, however, give no reason to believe that exendin-4 interacts with albumin (gel filtration, L. Simonsen, unpublished data). The link between exendin- 4 clearance and glomerular filtration receives some support from preliminary studies in patients with renal dysfunction, in which a progressive increase in half-life and reduction in metabolic clearance of exenatide (exendin-4) accompanied worsening creatinine clearance [34]. However, even in those patients with end-stage renal disease requiring haemodialysis, exenatide was still cleared slowly from the plasma, suggesting that mechanisms other than glomerular filtration can, at least under some circumstances, contribute to the clearance of exendin-4 [34]. In summary, we have shown that whereas GLP-1 undergoes differential organ extraction in the anaesthetised pig, exendin-4 is cleared exclusively by the kidneys. Furthermore, while renal clearance of GLP-1 exceeds the amount accounted for by glomerular filtration, indicating the involvement of additional mechanisms, renal extraction of exendin- 4 can be fully accounted for by glomerular filtration. 
Acknowledgements The authors would like to thank M. Olesen, L. Klarskov and S. Pilgaard for technical assistance, and A.-G. Juul (Novo Nordisk, Bagsværd, Denmark) for the gift of the GLP-1 peptides truncated at the C-terminus. The study was financed by the Novo Nordisk Foundation, the Velux Foundation, the Toyota Foundation, the Danish Medical Research Council, and the European Foundation for the Study of Diabetes.

The authors declare that they have no financial interests in this study.

\section{References}

1. Deacon CF, Ahren B, Holst JJ (2004) Inhibitors of dipeptidyl peptidase IV: a novel approach for the prevention and treatment of Type 2 diabetes? Expert Opin Investig Drugs 13:1091-1102

2. Vilsboll T, Agerso H, Krarup T, Holst JJ (2003) Similar elimination rates of glucagon-like peptide- 1 in obese type 2 diabetic patients and healthy subjects. J Clin Endocrinol Metab 88:220-224

3. Nauck MA, Kleine N, Orskov C, Holst JJ, Willms B, Creutzfeldt W (1993) Normalization of fasting hyperglycaemia by exogenous glucagon-like peptide 1 (7-36 amide) in type 2 (non-insulin-dependent) diabetic patients. Diabetologia 36: 741-744

4. Zander M, Madsbad S, Madsen JL, Holst JJ (2002) Effect of 6week course of glucagon-like peptide 1 on glycaemic control, insulin sensitivity, and beta-cell function in type 2 diabetes: a parallel-group study. Lancet 359:824-830

5. Mentlein R, Gallwitz B, Schmidt WE (1993) Dipeptidylpeptidase IV hydrolyses gastric inhibitory polypeptide, glucagon-like peptide-1(7-36)amide, peptide histidine methionine and is responsible for their degradation in human serum. Eur $\mathrm{J}$ Biochem 214:829-835

6. Deacon CF, Pridal L, Klarskov L, Olesen M, Holst JJ (1996) Glucagon-like peptide 1 undergoes differential tissue-specific metabolism in the anesthetized pig. Am J Physiol 271:E458E464

7. Gallwitz B, Schmidt WE, Conlon JM, Creutzfeldt W (1990) Glucagon-like peptide-1(7-36)amide: characterization of the domain responsible for binding to its receptor on rat insulinoma RINm5F cells. J Mol. Endocrinol 5:33-39

8. Hupe-Sodmann K, McGregor GP, Bridenbaugh R et al (1995) Characterisation of the processing by human neutral endopeptidase 24.11 of GLP-1(7-36) amide and comparison of the substrate specificity of the enzyme for other glucagon-like peptides. Regul Pept 58:149-156

9. Plamboeck A, Holst JJ, Carr RD, Deacon CF (2005) Neutral endopeptidase 24.11 and dipeptidyl peptidase IV are both mediators of the degradation of glucagon-like peptide 1 in the anaesthetised pig. Diabetologia 48:1882-1890

10. Hassan M, Eskilsson A, Nilsson C et al (1999) In vivo dynamic distribution of ${ }^{131}$ I-glucagon-like peptide-1 (7-36) amide in the rat studied by gamma camera. Nucl Med Biol 26:413-420

11. Meier JJ, Nauck MA, Kranz D et al (2004) Secretion, degradation, and elimination of glucagon-like peptide 1 and gastric inhibitory polypeptide in patients with chronic renal insufficiency and healthy control subjects. Diabetes 53:654-662

12. Ruiz-Grande C, Alarcon C, Alcantara A et al (1993) Renal catabolism of truncated glucagon-like peptide 1. Horm Metab Res 25:612-616

13. Eng J, Kleinman WA, Singh L, Singh G, Raufman JP (1992) Isolation and characterization of exendin-4, an exendin-3 analogue, from Heloderma suspectum venom. Further evidence for an exendin receptor on dispersed acini from guinea pig pancreas. J Biol Chem 267:7402-7405

14. Edwards CM, Stanley SA, Davis R et al (2001) Exendin-4 reduces fasting and postprandial glucose and decreases energy intake in healthy volunteers. Am J Physiol Endocrinol Metab 281:E155-E161
15. Thum A, Hupe-Sodmann K, Goke R, Voigt K, Goke B, McGregor GP (2002) Endoproteolysis by isolated membrane peptidases reveal metabolic stability of glucagon-like peptide-1 analogs, exendins-3 and -4. Exp Clin Endocrinol Diabetes 110:113-118

16. Deacon CF, Danielsen P, Klarskov L, Olesen M, Holst JJ (2001) Dipeptidyl peptidase IV inhibition reduces the degradation and clearance of GIP and potentiates its insulinotropic and antihyperglycemic effects in anesthetized pigs. Diabetes 50: 1588-1597

17. Trebbien R, Klarskov L, Olesen M, Holst JJ, Carr RD, Deacon CF (2004) Neutral endopeptidase 24.11 is important for the degradation of both endogenous and exogenous glucagon in anesthetized pigs. Am J Physiol Endocrinol Metab 287:E431E438

18. Hvidberg A, Nielsen MT, Hilsted J, Orskov C, Holst JJ (1994) Effect of glucagon-like peptide-1 (proglucagon 78-107amide) on hepatic glucose production in healthy man. Metabolism 43:104-108

19. Orskov C, Rabenhoj L, Wettergren A, Kofod H, Holst JJ (1994) Tissue and plasma concentrations of amidated and glycineextended glucagon-like peptide $\mathrm{I}$ in humans. Diabetes 43: 535-539

20. Orskov C, Jeppesen J, Madsbad S, Holst JJ (1991) Proglucagon products in plasma of noninsulin-dependent diabetics and nondiabetic controls in the fasting state and after oral glucose and intravenous arginine. J Clin Invest 87:415-423

21. Kreymann B, Williams G, Ghatei MA, Bloom SR (1987) Glucagon-like peptide-1 7-36: a physiological incretin in man. Lancet 2:1300-1304

22. Booth AG, Kenny AJ (1976) Proteins of the kidney microvillus membrane. Identification of subunits after sodium dodecylsulphate/polyacrylamide-gel electrophoresis. Biochem J 159: 395-407

23. Lambeir AM, Proost P, Scharpe S, De MI (2002) A kinetic study of glucagon-like peptide-1 and glucagon-like peptide-2 truncation by dipeptidyl peptidase IV, in vitro. Biochem Pharmacol 64:1753-1756

24. Hartmann B, Harr MB, Jeppesen PB et al (2000) In vivo and in vitro degradation of glucagon-like peptide-2 in humans. J Clin Endocrinol Metab 85:2884-2888

25. Neidigh JW, Fesinmeyer RM, Prickett KS, Andersen NH (2001) Exendin-4 and glucagon-like-peptide-1: NMR structural comparisons in the solution and micelle-associated states. Biochemistry 40:13188-13200

26. Roques BP, Noble F, Dauge V, Fournie-Zaluski MC, Beaumont A (1993) Neutral endopeptidase 24.11: structure, inhibition, and experimental and clinical pharmacology. Pharmacol Rev 45:87-146

27. Parkes D, Jodka C, Smith P et al (2001) Pharmacokinetic actions of exendin- 4 in the rat: comparison with glucagon like peptide-1. Drug Development and Research 53:260-267

28. Mentlein R (1999) Dipeptidyl-peptidase IV (CD26)-role in the inactivation of regulatory peptides. Regul Pept 85:9-24

29. Moreno C, Mistry M, Roman RJ (2002) Renal effects of glucagon-like peptide in rats. Eur J Pharmacol 434:163-167

30. Yamamoto H, Lee CE, Marcus JN et al (2002) Glucagon-like peptide-1 receptor stimulation increases blood pressure and heart rate and activates autonomic regulatory neurons. J Clin Invest 110:43-52

31. Peterson DR, Green EA, Oparil S, Hjelle JT (1986) Transport and hydrolysis of glucagon in the proximal nephron. Am J Physiol 251:F460-F467

32. Carone FA, Peterson DR, Flouret G (1982) Renal tubular processing of small peptide hormones. J Lab Clin Med 100: $1-14$

33. Emmanouel DS, Jaspan JB, Rubenstein AH, Huen AH, Fink E, Katz AI (1978) Glucagon metabolism in the rat. J Clin Invest 62:6-13

34. Linnebjerg H, Kothare P, Park S et al (2005) Exenatide pharmacokinetics in patients with mild to moderate renal dysfunction and end stage renal disease. ADA 2005. (Abstract) 